\title{
Paracoccidioides brasiliensis infection promotes thymic disarrangement and premature egress of mature lymphocytes expressing prohibitive TCRs
}

Rosaria Di Gangi ${ }^{1 \dagger}$, Thiago Alves da Costa ${ }^{1 \dagger}$, Rodolfo Thomé ${ }^{1}$, Gabriela Peron ${ }^{1}$, Eva Burger ${ }^{2}$ and Liana Verinaud ${ }^{1 *}$

\begin{abstract}
Background: Paracoccidioidomycosis, a chronic granulomatous fungal disease caused by Paracoccidioides brasiliensis yeast cells affects mainly rural workers, albeit recently cases in immunosuppressed individuals has been reported. Protective immune response against $P$. brasiliensis is dependent on the activity of helper $T$ cells especially IFN- $\gamma$-producing Th1 cells. It has been proposed that Paracoccidioides brasiliensis is able to modulate the immune response towards a permissive state and that the thymus plays a major role in it.
\end{abstract}

Methods: In this paper, we show that acute infection of BALB/C mice with P. brasiliensis virulent isolate (Pb18) might cause alterations in the thymic environment as well as the prohibitive TCR-expressing $T$ cells in the spleens.

Results: After seven days of infection, we found yeast cells on the thymic stroma, the thymic epithelial cells (TEC) were altered regarding their spatial-orientation and inflammatory mediators gene expression was increased. Likewise, thymocytes (differentiating $T$ cells) presented higher migratory ability in ex vivo experiments.

Notwithstanding, P. brasiliensis-infected mice showed an increased frequency of prohibitive TCR-expressing T cells in the spleens, suggesting that the selection processes that occur in the thymus may be compromised during the acute infection.

Conclusion: In this paper, for the first time, we show that acute infection with Paracoccidioides brasiliensis yeast cells promotes thymic alterations leading to a defective repertoire of peripheral $T$ cells. The data presented here may represent new mechanisms by which $P$. brasiliensis subverts the immune response towards the chronic infection observed in humans.

Keywords: Paracoccidioides brasiliensis, Paracoccidioidomycosis, Thymic atrophy

\section{Background}

The thymus is a primary lymphoid organ, where the differentiation and maturation of T-cell takes place. A number of cells and soluble proteins compose the thymic microenvironment and are responsible for forming a three dimensional network that provides mechanical support and fundamental stimulus for T-cell development [1]. In

\footnotetext{
* Correspondence: verinaud@unicamp.br

${ }^{\dagger}$ Equal contributors

'Department of Structural and Functional Biology, Institute of Biology, State University of Campinas, Rua Monteiro Lobato, 255, Cidade Universitária, SP, Brazil

Full list of author information is available at the end of the article
}

this process, intra-thymic migration of T-cell precursors plays an essential role [2].

The T-cell development in the thymus initiates after the entrance of double-negative (DN) T lymphocyte precursors at the cortico-medullary junction. Signals from cortical Thymic Epithelial Cells (cTEC) and IL-7 induce the $\mathrm{DN}$ thymocytes to migrate to the sub-capsular region of the cortex and express the specific chemokine receptors CXCR4, CCR7 and CCR9 [3, 4]. Then the V (D) J rearrangement of $\mathrm{T}$ Cell Receptor (TCR) $\beta$ chains occurs [5-7] and there is formation of pre-TCR complex, followed by the expression of CD4 and CD8 co-receptors $[1,8,9]$. 
The repertoire of the $\alpha \beta$ polypeptide chains in TCR associated with $\mathrm{CD} 3$ provides the recognition of foreign antigens and the specificity of the $\alpha \beta T C R$ depends on the $\mathrm{V} \beta$, the variable domain of the $\beta$ chain [5]. Thus, double-positives (DP) thymocytes carrying functional TCR $\alpha \beta$ interact with cTECs, receiving survival signals and maturating into single-positive (SP) thymocytes (9) which migrate though the cortex to the medullar region under the attraction of CCL19 and CCL21 chemokine ligands expressed by medullary (m) TECs, where they will undergo another repertoire screening called negative selection [10-13]. In this process the Autoimmune Regulator (Aire) gene plays a crucial role promoting the expression of tissue specific self-antigens within the thymus, if thymocytes express TCR segments that have high avidity for these self-antigens-MHC complex, they are eliminated by apoptosis [14].

Studies in BALB/C mices have shown that TCR segments $\mathrm{V} \beta 5$ and $\mathrm{V} \beta 12$ are normally eliminated in the process of negative selection, receiving the denomination of prohibited segments, numerous researches links them to damage to self events [15-18]. Finally, after the central tolerance processes the thymocytes become naïve $\mathrm{T}$ cells and migrate to secondary lymphoid organs. In fact, the thymus has a crucial rule in cell-mediated immunity that is the main host defense against intracellular pathogens, such as fungi.

The fungus Paracoccidioides brasiliensis $(\mathrm{Pb})$ is the mainly etiological agent of Paracoccidioidomycosis (PCM) that is a severe chronic and systemic mycosis. This mycosis account with cases widely distributed throughout Central and South America countries [19]. Infection disseminate to other tissues, resulting in damages of the skin, mucous membranes, lungs, Central Nervous System (CNS), spleen and lymph nodes compromising their functions [20]. During infection, the host fails to protect itself against $\mathrm{Pb}[20-22]$. Several mechanisms have been proposed for the impaired immune response, such as failure in antigen presentation, reduced $\mathrm{T}$ lymphocyte function and production of Th2-related cytokines like IL-4 and IL$10[23,24]$. Interestingly, we found that experimental infection with the high virulent clinical isolate $\mathrm{Pb} 18$ is followed by thymic involution [20].

Thymic atrophy has been described in many infections and metabolic disturbances, such as malaria, HIV, diabetes and malnutrition [20, 25-29]. The integrity of the thymic microenvironment is important for the maturation of thymocytes, where changes in the thymic microenvironment may compromise the $\mathrm{T}$ cell repertoire in the periphery, leading to immunosuppression or autoimmune diseases.

In this sense, we have recently shown that thymic atrophy in experimental malaria predisposes mice to exacerbated Experimental Autoimmune Encephalomyelitis (EAE), the mouse model of Multiple Sclerosis [30].
It is not clear which events are involved in the thymic atrophy seen in Pb18 infection nor whether organ atrophy would result in altered $\mathrm{T}$ cell repertoire in the periphery. In this study, we aimed to investigate the alterations caused by $P$. brasiliensis infection in the function and structure of the thymus as well as the effects of these alterations in $\mathrm{T}$ cell repertoire from peripheral lymphoid organs. It was found that in the course of infection, the thymus is rendered atrophic by means of epithelial cell spatial disarrangement and increased gene expression of inflammatory mediators. Notwithstanding, infected mice showed an increase in the frequency of prohibitive TCR-expressing $\mathrm{T}$ cells in the periphery. These results shed light on possible additional mechanisms of immunosuppression caused by $\mathrm{Pb}$ infection.

\section{Methods \\ Mice}

Eight-week old male BALB/c mice were used in this study. Mice were allocated in specific-pathogen free condition in transparent acrylic plastic isolators (dimensions: $37,9 \mathrm{~cm} \times 19,7 \mathrm{~cm} \times 12,7 \mathrm{~cm}, 5$ animals per cage) with absorbent material (wood shavings) in ventilated racks (Alesco, SP, Brazil) on a $12 \mathrm{~h}$ light/dark cycle and controlled temperature environment $\left(20^{\circ}-24{ }^{\circ} \mathrm{C}\right)$. Sterile water and food (Nuvilab CR-1; Nuvilab, PR, Brazil) were provided ad libitum. Once a week the bedding of the isolators was changed with autoclaved wood shavings. This study was conducted according to the ethical principles of animal research adopted by the Brazilian National Council for the Control of Animal Experimentation (CONCEA) and was approved and carried out in accordance with the guidelines of the Institutional Committee for Use of Laboratory Animals (CEUA, protocol number \# 2969-1). All procedures aforementioned are in accordance to the ARRIVE Guidelines for reporting animal research and the completed ARRIVE guidelines checklist is described in (Additional file 1: Supplemental data).

\section{Strain and infection}

The virulent strain $\mathrm{Pb} 18$ of $P$. brasiliensis used in this study was maintained at $37{ }^{\circ} \mathrm{C}$ in its yeast form in Fava's Netto medium and used at the seventh day of cells culture growth. The fungal virulence was maintained by followed recommendation [31-33]. The fungal mass was collected and suspended in sterile phosphate-buffered saline (PBS $0.01 \mathrm{M} \mathrm{pH} \mathrm{7.4),} \mathrm{mixed} \mathrm{three} \mathrm{times} \mathrm{for} 30 \mathrm{sec}$ onds with 60 seconds in between on a Vortex-mixer, centrifuged and then washed in PBS. Fungal viability was verified using trypan blue dye exclusion in a hemocytometer. Mice ( $n=5$ mice/group) were injected intraperitoneally with $5 \times 10^{6}$ viable yeast cells contained in $0.2 \mathrm{~mL}$ of PBS or with PBS alone. Infection was carried out for seven days when mice were euthanized by 
deep anesthesia with ketamine/xylazine $(100 \mathrm{mg} / \mathrm{kg}$ ketamine hydrochloride and $5 \mathrm{mg} / \mathrm{kg}$ xylazine hydrochloride), and the thymuses and spleens were excised. Groups of 5 mice were used for each experiment. BALB/ $\mathrm{c}$ mice were used as they are the most common experimental model of infection with $\mathrm{Pb}$, evaluated as intermediate in susceptibility patterns to PCM [34].

\section{Thymus weight and histological analysis}

Whole thymuses were weighted individually from control and infected mice. For histological analysis, the thymuses were fixed in buffered $4 \%$ paraformaldehyde followed by dehydration in ethanol, diaphanization in xylene and inclusion in Paraplast Plus (Sigma). Thin slices were made $(5 \mu \mathrm{m})$ in microtome and stained with Hematoxylin and Eosin while some slices were submitted to Grocott staining by sliver impregnation of viable yeast cells. The slices were analyzed under bright light field microscope equipped with camera (Olympus, Japan).

\section{Analysis of thymic epithelial cells distribution}

The thymuses were processed to cryotomy and slices of $5 \mu \mathrm{m}$ were made in cryostat. Briefly, free reactive sites in the slices were blocked with PBS plus Bovine Serum Albumin (BSA $1 \%$ ), followed by immunostaining for cytokeratin 8 (TROMA-I, DHSB Hybridoma, USA) and cytokeratin 14 (ab53115, Rabbit polyclonal to Cytokeratin 14, Abcam, UK). After, Cy2- and Cy3-conjugated secondary antibodies were added. At the end of incubation period, the slices were mounted in Vectashield (Vector Laboratories, Inc. Burlingame, USA) and were analyzed under epifluorescence microscope (Olympus, Japan). Images were analyzed in Image J for integrated density. Eight slides from each group were analysed $(n=4)$.

\section{Thymocytes subpopulation}

The thymuses were homogenized individually in staining buffer (PBS $0.02 \mathrm{M} \mathrm{pH} 7.2$ enriched with $2 \%$ Fetal Calf Serum) and cell number was estimated by hemocytometer. Flow cytometry staining was performed following a previously described protocol [35]. Briefly, one million cells were incubated with fluorochrome-conjugated monoclonal antibodies in a final volume of $100 \mu \mathrm{L}$ for $20 \mathrm{~min}$ at $4{ }^{\circ} \mathrm{C}$. Preparations were acquired with a Gallios flow cytometer (Beckman Coulter, USA) and data was analyzed using FlowJo VX (Tree Star Inc., Ashland, OR, USA). Cells were stained with anti-CD4 (clone H129.12 - BD Biosciences, CA, USA) and ant-CD8 (53-6.7-BD Biosciences, CA, USA).

\section{Real time PCR}

Thymic mRNA was extracted individually using the Qiagen RNAeasy Mini Kit (MD, USA) according to the manufacturer's instructions. Quantification was performed in
Nanodrop2000 (Thermo) and the mRNA was reverse transcripted into cDNA using High Capacity Kit (Applied Biosystems) by following manufacturer's instructions. Then the Taqman Gene Expression Master Mix (Applied Biosystems) was employed for real time PCR amplification using the Applied Biosystems 7500 Real-Time PCR Systems (CA, USA). Levels of mRNA expression were normalized to housekeeping gene GAPDH mRNA levels. The primers used in this study are: IL-2 (Mm00434256_m1), IL-7 (Mm01295803_m1), IL-10 (Mm00439614_m1), IL-17 (Mm00439618_m1), TNFa (Mm00443260_g1), AIRE (Mm00477461_m1), GAPDH (Mm99999915_g1). Expression levels of genes were represented as a relative copy numbers by using the method of delta threshold $\left(2^{-\Delta \Delta C t}\right)$.

\section{Chemokine in the thymus of mice infected with P. brasiliensis}

Total protein was extracted from infected and control mice using RIPA lysis buffer following manufacturer's instructions (Millipore, CA, USA). Total protein concentration was measured by the method of BRADFORD following manufacturer's instructions (Bio-Rad, CA, USA). The levels of CCL19 were measured by ELISA Kit (R\&D Biosystems, MN, USA) followed by manufacturer's instructions. To determine the expression of the CCR7 chemokine receptor in thymocytes, a flow cytometry analysis was performed in single cell suspensions originated from healthy and infected mice using CCR7 antibody (clone 4B12 - BD Biosciences, CA, USA) gated in $\mathrm{CD} 4 \mathrm{RA}^{+}$(clone 14.8-BD Biosciences, CA, USA) cells. The CCR7 expression was determined by Mean Fluorescence Intensity (MFI) parameter in FlowJo VX (Tree Star Inc., OR, USA).

\section{Cell migration assay}

Migration assays were performed in 24 well plates containing inserts with $5 \mu \mathrm{m}$ diameter pores according to the manufacturer's instructions (Corning Life Sciences, MA, USA). The membranes were incubated with $10 \mu \mathrm{g} /$ $\mathrm{mL}$ of BSA for $1 \mathrm{~h}$ at $37^{\circ} \mathrm{C}$ and then blocked with PBS/ BSA $0.5 \%$ for $45 \mathrm{~min}$ at $37{ }^{\circ} \mathrm{C}$. After blocking RPMI/ BSA $1 \%$ or RPMI/CCL19 $(100 \mu \mathrm{g} / \mathrm{mL}$; R\&D Systems, MN, USA) were added to the lower chamber of each trans-well assay. Thymuses cellular suspension was obtained by forcing the organ through a $70 \mu \mathrm{m}$ cell strainer and suspending in RPMI/BSA $1 \%$. Then $100 \mu \mathrm{L}$ of cell suspension (containing $2.5 \times 10^{6}$ cells) from control and infected mice, counted on a hemocytometer, were added to the upper chamber of each trans-well assay. Cells were allowed to migrate for $3 \mathrm{~h}$ at $37^{\circ} \mathrm{C}$ and upon completion; cells were recovered from the lower chamber and counted on a hemocytometer. Percent migration was calculated from the ratio of cells in the lower chamber to the initial input, and multiplying by 100 . 
Expression of prohibited TCRV $\beta 5$ and $V \beta 12$ segments in spleens of mice infected with P. brasiliensis

The analysis of prohibited TCR-expressing $\mathrm{T}$ cells followed a previous recommendation [36]. Briefly, the spleens from control and infected mice were collected and homogenized individually in PBS plus fetal bovine serum $5 \%$. After red blood cells (RBC) lysis, the cellular concentration was adjusted and $1 \times 10^{6}$ cells of each mouse were transferred to appropriate cytometer tubes. Cells were incubated with fluorochrome-conjugated monoclonal antibodies for $20 \mathrm{~min}$ at $4{ }^{\circ} \mathrm{C}$. Events were acquired on a flow cytometer (Gallios, Beckman Coulter, CA, USA) and data was analyzed using FlowJo VX (Tree Star Inc., OR, USA). Antibodies used in this study were anti-CD4 (clone H129.12-BD Biosciences, CA, USA), CD8 (clone 53-6.7 - BD Biosciences, CA, USA), TCRV $\beta 12$ (clone MR9-4 eBioscience, CA, USA), TCRV 35 (clone MR11-1 eBioscience, CA, USA).

\section{Statistical analysis}

Statistical analyses were performed using GraphPad 6 software and Student's t-test was used for 2-group comparisons. A P value of less than 0.05 was considered statistically significant. Values are expressed as means \pm standard error mean (SEM).

\section{Results}

Acute Paracoccidioides brasiliensis infection leads to atrophy, architecture changes and fungal invasion of the thymus

To evaluate the effect of $\mathrm{Pb}$ infection on the thymus, male BALB/c mice were infected with $5 \times 10^{6}$ yeast cells intraperitoneally. The animals were sacrificed seven days after infection and the thymuses were collected and weighted. The data obtained showed that the infection by $\mathrm{Pb}$ leads to significant reduction of the thymic weight in infected animals compared to control animals (Fig. 1a). We aimed to evaluate the possible structural changes in the thymus of mice infected with $\mathrm{Pb}$. When the slides were stained for HE no structural changes between cortical and medullar region were observed (Fig. 1b) even though, viable fungal cells were detected by Grocott staining (Fig. 1c). Then we decided to investigate whether there was alteration in the expression and distribution of cortical and medullary epithelial cells by immunostaining of their cytokeratin 8 and 14, respectively. Thymuses of infected mice showed alterations in the arrangement of the medullar and cortical regions when compared with uninfected animals. These changes are evident when the immunostaining for cortical epithelial cells showed no significant alteration in the expression of cytokeratin but its spatial distribution appears to be
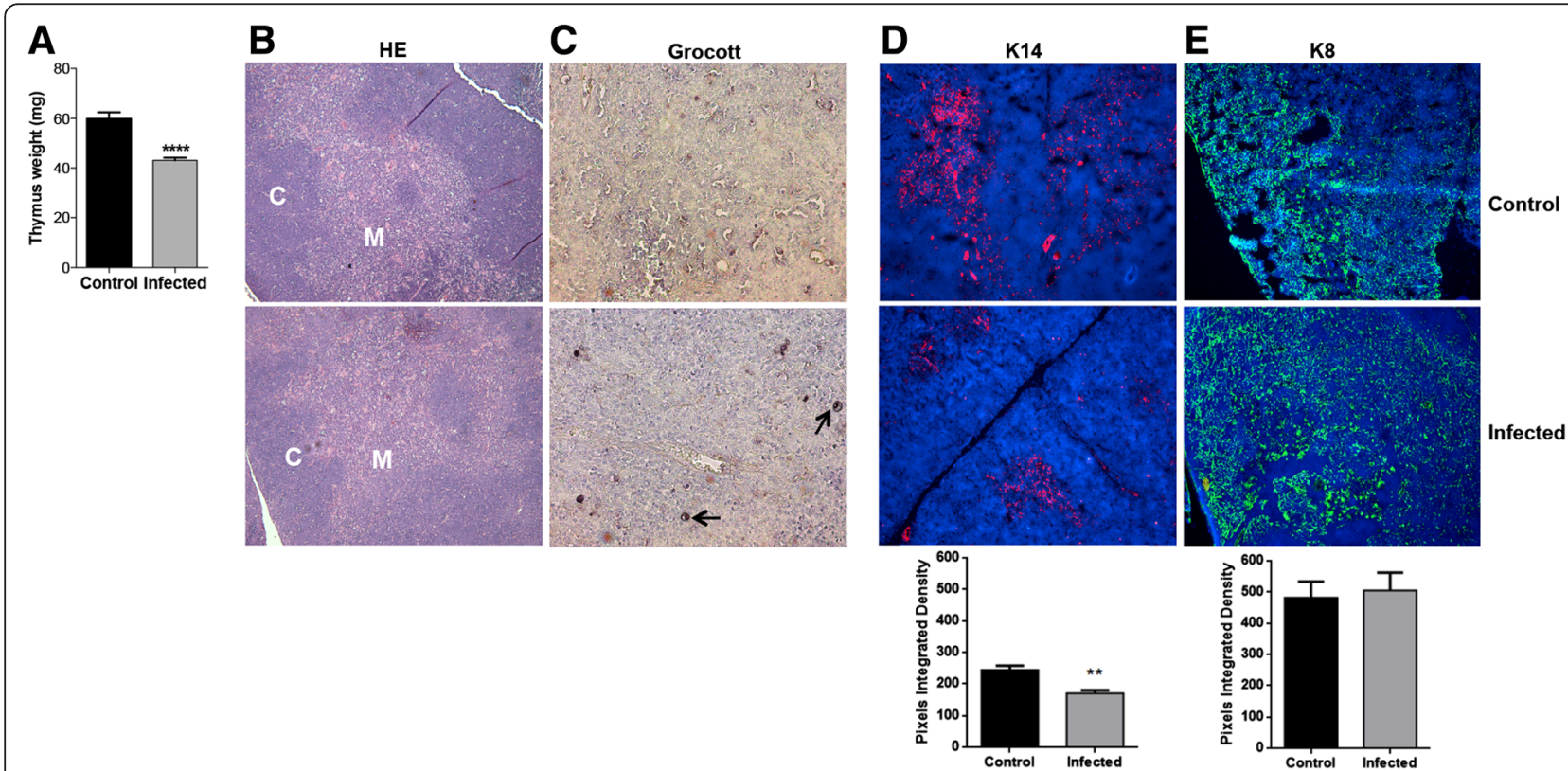

Fig. 1 P. brasiliensis acute infection leads to thymic atrophy, alterations on thymus architecture and fungal invasion. Male Balb/c mice ( $n=5$ mice/ group) were injected i.p. with Pb yeast cells. Seven days later, thymuses were analyzed for alterations on architecture and presence of yeast cells. (a) Loss of thymic weight following injection with yeast cells or PBS. (b) Cortico-medullary junction preserved by Hematoxylin-Eosin staining following injection with yeast cells or PBS. (c) Presence of yeast cells by Grocott staining method following injection with yeast cells or PBS, indicated by the arrows. (d) Unaltered expression of cytokeratin 14 by immunofluorescence following injection with yeast cells or PBS and (e) Diminished expression of cytokeratin 8 by immunofluorescence following injection with yeast cells or PBS. Photomicrography total magnification 100x. C-cortical and M-medullary areas. Data was analyzed by Student $t$ test. Values of $p \leq 0,01\left(^{* *}\right)$ and $p \leq 0,0001\left(^{* * *}\right)$ were considered statistically significant. Results are expressed by Mean \pm SEM. Representative data from three independent experiments with similar results 
misplaced with the medullar region (Fig. 1d). Meanwhile the analysis of the immunostaining for cytokeratin of medullar epithelial cells by integrated density shows that the expression of cytokeratin of medullar epithelial cells was significantly diminished (Fig. 1e).

\section{Genetic expression of the autoimmune regulator-AIRE and} the cytokines IL-7, IL-2, IL-17 and TNFa are augmented in the thymuses of mice infected with $\mathrm{P}$. brasiliensis

In order to verify whether the gene expression of important cytokines and the transcription factor autoimmune regulator (AIRE) are altered in the thymus of infected mice, total mRNA was extracted from the thymuses of infected and non-infected mice and RT-PCR was performed to analyze the genetic expression of $I L-7$, $I L-2, I L-10, I L-17, T N F \alpha$ and AIRE. Results showed that the gene expression of IL-2, IL-7 and AIRE were significantly augmented in thymuses of $\mathrm{Pb}$ infected mice (Fig. 2a). Likewise gene expression of the inflammatory cytokines IL-17 and TNF $\alpha$ also showed higher levels in thymuses of $\mathrm{Pb}$ infected mice. The anti-inflammatory cytokine IL-10 had no altered levels in the thymuses of $\mathrm{Pb}$ infected mice (Fig. 2b).

\section{Chemokine signaling is altered in thymuses from infected} mice and is correlated with increased migration of thymocytes

The thymic involution and the histological changes observed in the presence of yeast in the thymuses from animals infected with $\mathrm{Pb}$ suggest that the thymus is a target organ also in PCM infection. The presence of the fungus in the thymus, an essential organ for maturation of lymphocytes and repertoire selection, may interfere with the differentiation process of thymocytes. Analysis of thymocytes subpopulations for CD4 and CD8 revealed that there were no changes in the relative frequencies of thymocytes subpopulations between healthy and infected mice (Fig. 3a), though there was a decrease in the absolute number of all thymocytes subpopulations at seven days of infection when compared to the control group (Fig. 3b). As the numbers of thymocytes subpopulations were altered, we evaluated whether there was an unbalanced chemokine expression caused by the $\mathrm{Pb}$ infection. To answer this question the expression of the chemokine ligand CCL19 and its receptor CCR7 was assessed. Both CCL19 and CCR7 expression were significantly increased in the thymuses from infected mice (Fig. 3c and Fig. d). Later, we evaluated the migration ability of thymocytes in Transwell chambers. We incubated thymocytes from control and infected mice in the presence of CCL19. Results show that cells from $\mathrm{Pb}$-infected mice presented a four-fold increased migration than to control cells (Fig. 3e).

\section{Expression of "prohibited" TCRV $\beta$ segments in $T$ cells from spleens during acute $\mathrm{P}$. brasiliensis infection}

During negative selection, thymocytes with high affinity for self-peptides/MHC undergo apoptosis, this process is crucial to eliminate $\mathrm{T}$ lymphocytes that could drive
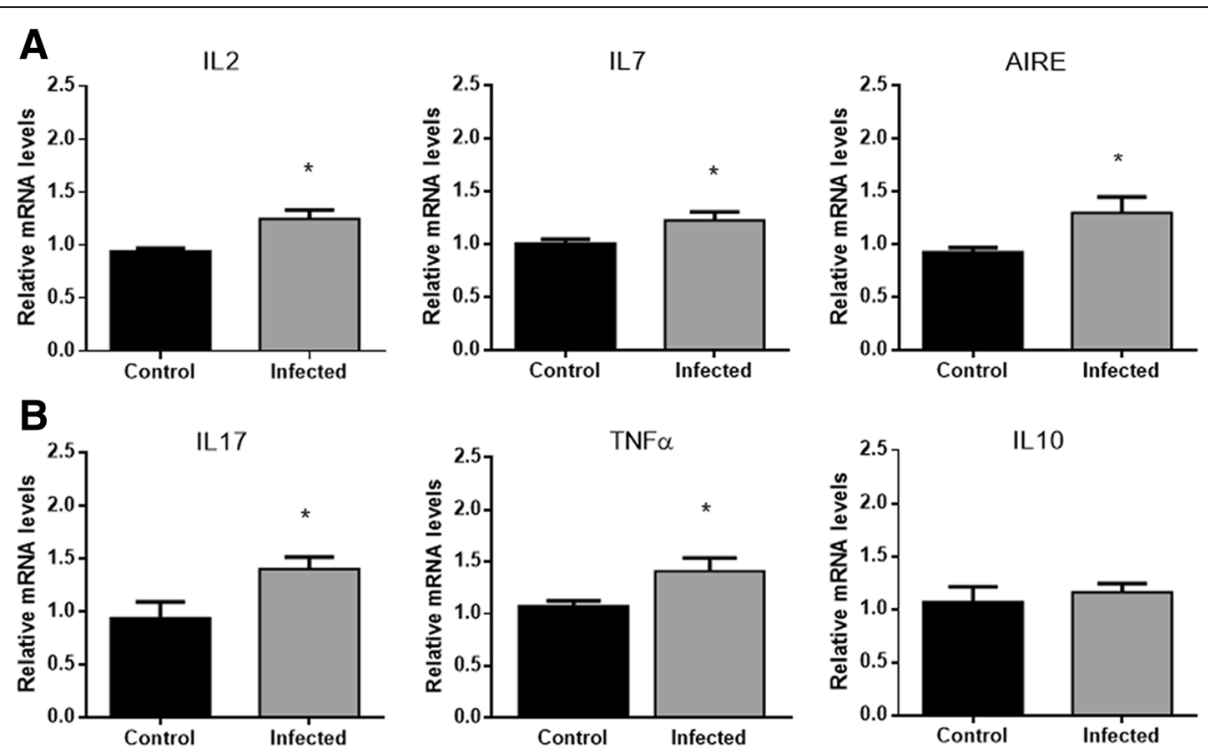

Fig. 2 Gene expression of inflammatory mediators are augmented in the thymuses of mice infected with $P$. brasiliensis. Male Balb/c mice $(n=5$ mice/group) were injected i.p. with Pb cells. Seven days later, thymuses were processed to mRNA extraction and analyzed for alterations on gene expression of AIRE, IL-7, IL-2, IL-17, IL-10 and TNFa, with GAPDH as housekeeping gene by real-time PCR. (a) Relative mRNA level of IL-2, IL-7 and AIRE in thymus of infected mice. (b) Relative mRNA level of IL-17, TNFa and IL-10. Expression levels of genes were represented as a relative copy numbers by using the method of delta threshold $\left(2^{-\Delta \Delta c t}\right)$. Data was analyzed by Student $t$ test. Values of $p \leq 0,05\left(^{*}\right)$ were considered statistically significant. Results are expressed by Mean \pm SEM. Representative data from three independent experiments with similar results 


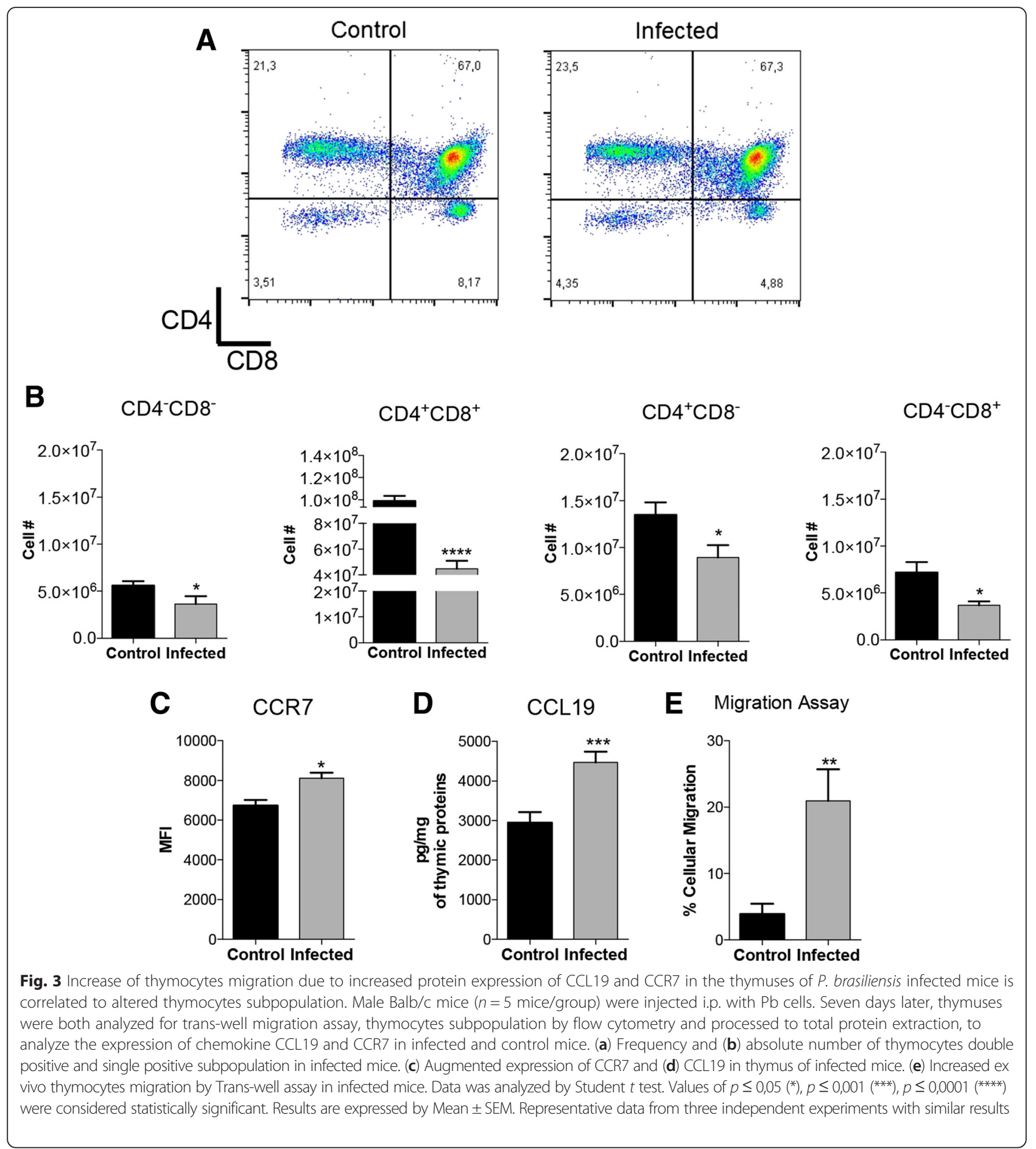

immune responses towards self-peptides in the periphery. In this context, we analyzed the percentage of $\mathrm{T}$ lymphocytes expressing prohibitive TCRV $\beta 5$ and V $\beta 12$ segments. In normal conditions, there are low numbers of these cells in the thymus and also in the periphery of the immune system of BALB/c mice [36, 37]. Our results showed that spleens from infected mice presented an increased frequency of $\mathrm{CD}^{+}$and $\mathrm{CD} 8^{+} \mathrm{T}$ lymphocytes expressing TCRV $\beta 5$ and V $\beta 12$ compared to controls (Fig. 4a and b). This observation suggests that the thymus is exporting $\mathrm{T}$ cells that should have been eliminated during the maturation process.

\section{Discussion}

Paracoccidioidomycosis (PCM) is one of the most prevalent systemic mycosis in Latin America countries [38]. 

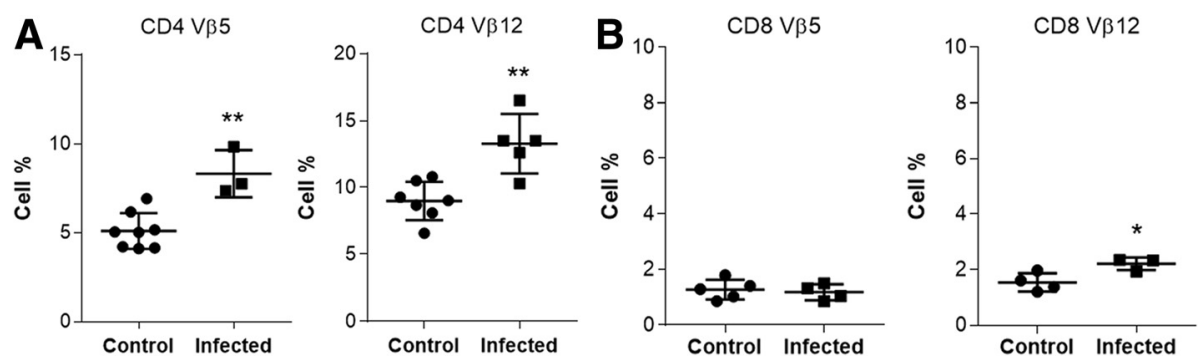

Fig. 4 Expression of "prohibited" TCRV $\beta$ segments in T cells from spleens during acute $P$. brasiliensis infection. Male Balb/c mice ( $n=5$ mice/group) were injected i.p. with Pb cells. Seven days later, spleens were analyzed for expression of TCRV $\beta 5$ and V $\beta 12$ segments in T cells from infected and control mice. Increased expression of TCRV $\beta 5$ and V 12 segments in (a) CD4 and TCRV $\beta 12$ segment in (b) CD8 T lymphocyte in spleens of infected mice. Data was analyzed by Student $t$ test. Values of $p \leq 0,05\left(^{*}\right), p \leq 0,01\left(^{* *}\right)$ were considered statistically significant. Results are expressed by Mean \pm SEM. Representative data from three independent experiments with similar results

This disease affects mainly rural workers but immunosuppressed individuals can also develop it as an opportunistic disease [39-41]. P. brasiliensis is the causative agent of PCM. Pb has demonstrated tropism to organs of the immune system, as lymph nodes, spleen and the thymus. Although the thymus was considered as an immune privileged site, it is now consistent to say that antimicrobial responses take place in the thymus [42]. In this paper, we show that experimental infection with $\mathrm{Pb}$ yeast cells alters the thymic stroma with a decreased thymocytes cell subpopulation, increased thymocytes migration and higher expression of prohibited TCRV $\beta 5$ and $\mathrm{V} \beta 12$ segments in $\mathrm{T}$ lymphocytes from spleen.

The thymic microenvironment comprises a threedimensional network of thymic epithelial cells (TECs), macrophages, dendritic cells, extracellular matrix components, enzymes and molecules, such as cytokines and chemokines in direct contact with thymocytes [43]. Local infection of the thymus and inflammatory mediators that follow systemic infection alter these thymic features and may impair the differentiation of pathogenspecific $\mathrm{T}$ cells, which may diminish host resistance to infection $[42,44,45]$. In this study, we demonstrated the ability of the strain $\mathrm{Pb} 18$ of $P$. brasiliensis to cause thymic atrophy while maintaining its viability in the thymic stroma at seven days after infection, in later time points of the infection more pathogens were found, including ones with budding yeasts, suggesting ability to thrive and multiply in the thymic microenvironment (manuscript in preparation). Even though the thymic weight in infected mice was $30 \%$ lower than healthy mice, we observed no disruption in the corticomedullary delimitation. We did observe that mTECs numbers were reduced in the medullar region of the thymus. Despite its role in the negative selection of SP thymocytes, mTECs are also involved in the maturation of SP thymocytes, which will be exported to the periphery as functional self-tolerant $\mathrm{T}$ cells [46]. We hypothesize that diminished presence of mTECs in $\mathrm{Pb}$ infected thymus might impair central tolerance and exportation of auto reactive $\mathrm{T}$ cells could be altered favoring the elimination of $\mathrm{Pb}$-reactive $\mathrm{T}$ cells.

In order to evaluate these changes, we found that the presence of $\mathrm{Pb}$ in the thymus led to a higher gene expression of inflammatory cytokines genes such as TNF $\alpha$ and IL-17 causing a pro-inflammatory profile to control fungal dissemination. Interestingly, AIRE expression was found augmented in thymus from infected mice. We can only hypothesize that AIRE expression comprehends (a) an effort of the thymus to maintain negative selection in face of the reduction in mTEC numbers or (b) could be induced by the fungus to change the repertoire of $\mathrm{T}$ cells produced in the thymus and favor its survival. Unfortunately, literature lack concise data regarding both hypotheses.

Many studies have demonstrated that infection led to thymic atrophy by depletion of thymocytes subpopulation $[9,26-28,44]$. In our case, the loss of thymic weight was followed by: (a) diminished number of all four thymocytes subpopulations and (b) augmented thymocytes migration. The chemokine ligand CCL19 and its receptor CCR7 participate in thymocytes migration during the development of immature DP thymocytes to mature SP thymocytes throughout the thymus. Ueno et al. have shown that CCL19 is produced by mTECs and is located in the thymic medulla whereas CCR7 expression augments in cell surface of immature cortical DP thymocytes $[47,48]$. Here we demonstrated that the expression of CCR7 and CCL19 were higher in the infected group than in control group. Our findings suggest that, during $\mathrm{Pb}$ infection, the thymocytes undergo maturation in an accelerated way. Actually, in Plasmodium berghei-infected mice we found that the thymus exports much more $\mathrm{T}$ cells than thymus from control mice (manuscript in preparation). Notwithstanding, $\mathrm{T}$ cell repertoire in $P$. berghei-infected mice was altered with the presence of prohibited-TCR-expressing $\mathrm{T}$ cells (manuscript in preparation). This altered $\mathrm{T}$ cell repertoire could lead to 
aggravation of autoimmune diseases. Indeed, we showed that following $P$. berghei infection, C57BL/6 mice develop a severe form of Experimental Autoimmune Encephalomyelitis, the mouse model of Multiple Sclerosis, by means of prematurely-egressed thymic Doublepositive $T$ cells [30]. Also, cells expressing prohibited TCRV $\beta$ segments were found in the lymph nodes of mice infected with Trypanosoma cruzi, probably as a result of the disbalance on thymic molecules, such as cytokines, chemokines and extracellular matrix elements that could promote the double-positive $\mathrm{T}$ cells escape $[36,49]$. That could be the case of $\mathrm{Pb}$ infection. We found that spleen cells from $\mathrm{Pb}$-infected mice contained a higher proportion of prohibited-TCR-expressing $\mathrm{T}$ cells than spleens cells from health mice.

\section{Conclusion}

Taken together, our data show for the first time that, in acute $\mathrm{Pb}$ infection, the thymus is rendered atrophic as a consequence of elevated fungal burden, deregulated cytokine and chemokine expression, diminished absolute thymocytes subpopulations and enhanced migratory ability of thymocytes. In addition, as a possible consequence of thymic disarrangement, we observed an altered T cell repertoire in the periphery of the immune system. Further studies are required to ascertain the possible consequences of the thymic atrophy in experimental PCM.

\section{Ethics approval and consent to participate}

This study was approved and carried out in accordance with the guidelines of the Institutional Committee for Use of Laboratory Animals (CEUA, \# 2969-1).

\section{Consent for publication \\ Not applicable.}

\section{Availability of data and materials}

All the data supporting our findings is contained within the manuscript.

\section{Additional file}

Additional file 1: The ARRIVE Guidelines Checklist. (PDF 1054 kb)

\begin{abstract}
Abbreviations
AIRE: autoimmune regulator; BSA: bovine serum albumin; CNS: central nervous system; Cy: cyanine; DN: double-negative; DP: double-positive; GAPDH: glyceraldehyde-3-phosphate dehydrogenase; HE: hematoxylin-eosin; HIV: human immunodeficiency virus; IL: interleukin; MHC: major histocompatibility complex; mRNA: messenger ribonucleic acid; $\mathrm{Pb}$ : paracoccidioides brasiliensis; PBS: phosphate-buffered saline; PCM: Paracoccidioidomycosis; SP: single-positive; TCR: T-cell receptor; TEC: thymic epithelial cell; Th cell: T helper cell; TNF: tumor necrosis factor.
\end{abstract}

\section{Competing interests}

The authors declare that they have no competing interests.

\section{Authors' contributions}

RDG carried out the cell migration assay, the analysis of thymic epithelial cells distribution, the chemokines production/quantification assay and performed the statistical analysis. TAC carried out the flow cytometry analysis, participated in the coordination and helped to draft the manuscript. GP carried out the gene expression assays and helped draft the manuscript. RT participated in the design and coordination of the study and helped to draft the manuscript. EB participated in the design of the study and helped analyzing the data. LV conceived the study and participated in its design and coordination and helped to draft the manuscript. All authors read and approved the final manuscript.

\section{Acknowledgements}

The TROMA-I monoclonal antibody developed by Philippe Brulet and Rolf Kemler at Institut Pasteur was obtained from the Developmental Studies Hybridoma Bank created by the NICHD of the $\mathrm{NIH}$ and maintained at The University of lowa, Department of Biology, lowa City, IA 52242.

The authors would like to thank Mr. Marcos César Meneghetti for his help with animal care, and Ms. Isadora Tassinari Ferreira for helping with the

Trans-well migration experiments.

\section{Funding}

This work was supported by São Paulo Research Foundation (FAPESP, \#2012/ 22131-7, \#2013/01401-9, \#2013/08194-9 and \#2014/02631-0). The funders had no role in the study design, data collection and analysis, decision to publish, or preparation of the manuscript.

\section{Author details}

'Department of Structural and Functional Biology, Institute of Biology, State University of Campinas, Rua Monteiro Lobato, 255, Cidade Universitária, SP, Brazil. ${ }^{2}$ Instituto de Ciências Biomédicas, Universidade Federal de Alfenas, Alfenas, MG, Brazil.

Received: 19 December 2015 Accepted: 10 May 2016

Published online: 17 May 2016

\section{References}

1. Anderson G, Moore NC, Owen JJ, Jenkinson EJ. Cellular interactions in thymocyte development. Annu Rev Immunol. 1996;14:73-99.

2. Cowan JE, Jenkinson WE, Anderson G. Thymus medulla fosters generation of natural Treg cells, invariant gammadelta T cells, and invariant NKT cells: what we learn from intrathymic migration. Eur J Immunol. 2015;45(3):652-60.

3. Svensson M, Marsal J, Uronen-Hansson $\mathrm{H}$, et al. Involvement of CCR9 at multiple stages of adult T lymphopoiesis. J Leukoc Biol. 2008;83(1):156-64.

4. Hong C, Luckey MA, Park JH. Intrathymic IL-7: the where, when, and why of IL-7 signaling during T cell development. Semin Immunol. 2012;24(3):151-8.

5. Dudley EC, Petrie HT, Shah LM, Owen MJ, Hayday AC. T cell receptor beta chain gene rearrangement and selection during thymocyte development in adult mice. Immunity. 1994;1(2):83-93.

6. Livak F, Petrie HT, Crispe IN, Schatz DG. In-frame TCR delta gene rearrangements play a critical role in the alpha beta/gamma delta T cell lineage decision. Immunity. 1995;2(6):617-627.5.

7. Capone M, Hockett Jr RD, Zlotnik A. Kinetics of T cell receptor beta, gamma, and delta rearrangements during adult thymic development: $T$ cell receptor rearrangements are present in CD44 (+) CD25 (+) Pro-T thymocytes. Proc Natl Acad Sci U S A. 1998;95(21):12522-7.

8. Gameiro J, Nagib P, Verinaud L. The thymus microenvironment in regulating thymocyte differentiation. Cell Adhes Migr. 2010;4(3):382-90.

9. De Meis J, Aurelio Farias-de-Oliveira D, Nunes Panzenhagen PH, Maran N, VillaVerde DM, Morrot A, Savino W. Thymus atrophy and double-positive escape are common features in infectious diseases. J Parasitol Res. 2012;2012:574020.

10. Stein JV, Nombela-Arrieta C. Chemokine control of lymphocyte trafficking: a general overview. Immunology. 2005;116(1):1-12.

11. Carlsen HS, Haraldsen G, Brandtzaeg P, Baekkevold ES. Disparate lymphoid chemokine expression in mice and men: no evidence of CCL21 synthesis by human high endothelial venules. Blood. 2005;106(2):444-6.

12. Link A, Vogt TK, Favre S, Britschgi MR, Acha-Orbea H, Hinz B, Cyster JG, Luther SA. Fibroblastic reticular cells in lymph nodes regulate the homeostasis of naive T cells. Nat Immunol. 2007;8(11):1255-65.

13. Forster R, Davalos-Misslitz AC, Rot A. CCR7 and its ligands: balancing immunity and tolerance. Nat Rev Immunol. 2008;8(5):362-71. 
14. Anderson M, Su M. Aire and T cell development. Curr Opin Immunol. 2011; 23:198-206.

15. Chou YK, Morrison WJ, Weinberg AD, Dedrick R, Whitham R, Bourdette DN, Hashim G, Offner H, Vandenbark AA. Immunity to TCR peptides in multiple sclerosis. II. T cell recognition of $\mathrm{V}$ beta 5.2 and $\mathrm{V}$ beta 6.1 CDR2 peptides. J Immunol. 1994;152:2520-9.

16. Hodes RJ, Abe R, Hodes RJ, Abe R. Mouse Endogenous Superantigens: Ms and Mls like Determinants Encoded by Mouse Retroviruses. Curr Protoc Immunol. 1996;1F:1-A.

17. Keesen A, Faria G, Bacellar C, Dutra G. CD4+ T cells defined by their V $\mathrm{T}$ cell receptor expression are associated with immunoregulatory profiles and lesion size in human leishmaniasis. Clin Exp Immunol. 2011;165:338-51.

18. Menezes CA, Sullivan AK, Falta MT, Mack DG, Freed BM, Rocha MO, Gollob KJ, Fontenot AP, Dutra WO. Highly conserved CDR3 region in circulating CD4 (+) VB5 (+) T cells may be associated with cytotoxic activity in Chagas disease. Clin Exp Immunol. 2012;169:109-18.

19. Shikanai-Yasuda MA, Telles Filho Fde Q, Mendes RP, Colombo AL, Moretti ML. Guidelines in paracoccidioidomycosis. Rev Soc Bras Med Trop. 2006; 39(3):297-310.

20. Brito VN, Souto PC, Cruz-Hofling MA, Ricci LC, Verinaud L. Thymus invasion and atrophy induced by Paracoccidioides brasiliensis in BALB/C mice. Med Mycol. 2003;41(2):83-7.

21. Brummer E, Castaneda E, Restrepo A. Paracoccidioidomycosis: an update Clin Microbiol Rev. 1993;6(2):89-117.

22. Bocca AL, Amaral AC, Teixeira MM, Sato PK, Shikanai-Yasuda MA, Soares Felipe MS. Paracoccidioidomycosis: eco-epidemiology, taxonomy and clinical and therapeutic issues. Future Microbiol. 2013;8(9):1177-91.

23. Alves da Costa T, Di Gangi R, Martins P, et al. Protection against Paracoccidioides brasiliensis infection in mice treated with modulated dendritic cells relies on inhibition of interleukin-10 production by CD8 (+) T cells. Immunology. 2015;146(3):486-95.

24. Campanelli AP, Martins GA, Souto JT, Pereira MS, Livonesi MC, Martinez R, Silva JS. Fas-Fas ligand (CD95-CD95L) and cytotoxic T lymphocyte antigen-4 engagement mediate $T$ cell unresponsiveness in patients with paracoccidioidomycosis. J Infect Dis. 2003;187(9):1496-505.

25. Nagib PR, Gameiro J, Stivanin-Silva LG, De Arruda MS, Villa-Verde DM, Savino W, Verinaud $\mathrm{L}$. Thymic microenvironmental alterations in experimentally induced diabetes. Immunobiology. 2010;215(12):971-9.

26. Francelin C, Paulino LC, Gameiro J, Verinaud L. Effects of Plasmodium berghei on thymus: high levels of apoptosis and premature egress of CD4 (+) CD8 (+) thymocytes in experimentally infected mice. Immunobiology. 2011;216(10):1148-54.

27. Brilot $F$, Jaidane $H$, Geenen V, Hober D. Coxsackievirus B4 infection of murine foetal thymus organ cultures. J Med Virol. 2008;80(4):659-66.

28. Ho Tsong Fang R, Colantonio AD, Uittenbogaart $\mathrm{CH}$. The role of the thymus in HIV infection: a 10 year perspective. Aids. 2008;22(2):171-84.

29. Lima AC, Francelin C, Ferrucci DL, Stach-Machado DR, Verinaud L. Thymic alterations induced by Plasmodium berghei: expression of matrix metalloproteinases and their tissue inhibitors. Cell Immunol. 2012;279(1):53-9.

30. Thome R, Bombeiro AL, Issayama LK, et al. Exacerbation of autoimmune neuro-inflammation in mice cured from blood-stage Plasmodium berghei infection. PLoS One. 2014;9(10), e110739.

31. Brummer E, Restrepo A, Hanson LH, Stevens DA. Virulence of Paracoccidiodes brasiliensis: the influence of in vitro passage and storage. Mycopathologia. 1990;109(1):13-7.

32. Castaneda E, Brummer E, Pappagianis D, Stevens DA. Impairment of cellular but not humoral immune responses in chronic pulmonary and disseminated paracoccidioidomycosis in mice. Infect Immun. 1988;56(7):1771-7.

33. Ferreira MC, Brito VN, Gameiro J, Costa MR, Vasconcellos EC, Cruz-Hofling MA, Verinaud L. Effects of HeNe laser irradiation on experimental paracoccidioidomycotic lesions. J Photochem Photobiol B. 2006;84(2):141-9.

34. Singer-vermes $L$ et al. Experimental murine paracoccidioidomycosis: relationship among the dissemination of the infection, humoral and cellular immune responses. Clin Exp Immunol. 1993:94(1):75-9.

35. Thome R, Issayama LK, Alves Da Costa T, et al. Dendritic cells treated with crude Plasmodium berghei extracts acquire immune-modulatory properties and suppress the development of autoimmune neuroinflammation. Immunology. 2014;143(2):164-73.

36. Mendes-da-Cruz DA, De Meis J, Cotta-de-Almeida V, Savino W. Experimental Trypanosoma cruzi infection alters the shaping of the central and peripheral T-cell repertoire. Microbes Infect. 2003;5(10):825-32.
37. Matsutani T, Ohmori T, Ogata M, Soga H, Yoshioka T, Suzuki R, Itoh T. Alteration of T-cell receptor repertoires during thymic T-cell development. Scand J Immunol. 2006;64(1):53-60.

38. Colombo AL, Tobón A, Restrepo A, Queiroz-Telles F, Nucci M. Epidemiology of endemic systemicfungal infections in Latin America. Med Mycol. 2011;49: 785-98.

39. Calich VL, Vaz CA, Burger E. Immunity to Paracoccidioides brasiliensis infection. Res Immunol. 1998;149(4-5):407-17. discussion 99-500.

40. Martinez R. Epidemiology of Paracoccidioidomycosis. Rev Inst Med Trop Sao Paulo. 2015;57 Suppl 19:11-20.

41. Zavascki AP, Bienardt JC, Severo LC. Paracoccidioidomycosis in organ transplant recipient: case report. Rev Inst Med Trop Sao Paulo. 2004;46(5):279-81.

42. Nunes-Alves C, Nobrega C, Behar SM, Correia-Neves M. Tolerance has its limits: how the thymus copes with infection. Trends Immunol. 2013;34(10): 502-10.

43. Starr TK, Jameson SC, Hogquist KA. Positive and negative selection of T cells. Annu Rev Immunol. 2003;21:139-76.

44. Savino W. The thymus is a common target organ in infectious diseases. PLoS Pathog. 2006;2(6), e62.

45. Savino W, Dardenne M, Velloso LA, Dayse S-BS. The thymus is a common target in malnutrition and infection. Br J Nutr. 2007;98 Suppl 1:S11-6.

46. Zuklys S, Balciunaite G, Agarwal A, Fasler-Kan E, Palmer E, Hollander GA. Normal thymic architecture and negative selection are associated with Aire expression, the gene defective in the autoimmune-polyendocrinopathy-candidiasisectodermal dystrophy (APECED). J Immunol. 2000;165(4):1976-83.

47. Ueno T, Hara K, Willis MS, et al. Role for CCR7 ligands in the emigration of newly generated T lymphocytes from the neonatal thymus. Immunity. 2002; 16(2):205-18.

48. Ueno T, Saito F, Gray DH, et al. CCR7 signals are essential for cortex-medulla migration of developing thymocytes. J Exp Med. 2004;200(4):493-505.

49. Cruz D, Silva J, Almeida V, Savino W. Altered thymocyte migration during experimental acute Trypanosoma cruzi infection: combined role of fibronectin and the chemokines CXCL12 and CCL4. Eur J Immunol. 2006:36:1486-93.

\section{Submit your next manuscript to BioMed Central and we will help you at every step:}

- We accept pre-submission inquiries

- Our selector tool helps you to find the most relevant journal

- We provide round the clock customer support

- Convenient online submission

- Thorough peer review

- Inclusion in PubMed and all major indexing services

- Maximum visibility for your research

Submit your manuscript at www.biomedcentral.com/submit
) Biomed Central 